Article

\title{
Chemical and Morphological Characterization of Magnetron Sputtered at Different Bias Voltages Cr-Al-C Coatings
}

\author{
Aleksei Obrosov ${ }^{1, *}$, Roman Gulyaev ${ }^{2}$, Andrzej Zak ${ }^{3}$, Markus Ratzke ${ }^{4}$, Muhammad Naveed ${ }^{1}$, \\ Wlodzimierz Dudzinski ${ }^{3}$ and Sabine Weiß ${ }^{1}$ \\ 1 Chair of Physical Metallurgy and Materials Technology, Brandenburg Technical University, \\ Cottbus 03046, Germany; muhammad.naveed@b-tu.de (M.N.); sabine.weiss@b-tu.de (S.W.) \\ 2 Boreskov Institute of Catalysis SB RAS, Novosibirsk 630090, Russia; gulyaev@catalysis.ru \\ 3 Department of Material Science, Welding and Strength of Material, Faculty of Mechanical Engineering, \\ Wroclaw University of Science and Technology, Wrocław 50370, Poland; andrzej.zak@pwr.edu.pl (A.Z.); \\ wlodzimierz.dudzinski@pwr.edu.pl (W.D.) \\ 4 Chair of Experimental Physics II/Materials Science, Brandenburg Technical University, \\ Cottbus 03046, Germany; markus.ratzke@b-tu.de \\ * Correspondence: aleksei.obrosov@b-tu.de; Tel.: +49-355-694-251
}

Academic Editor: Raman Singh

Received: 21 December 2016; Accepted: 3 February 2017; Published: 10 February 2017

\begin{abstract}
MAX phases $(\mathrm{M}=$ transition metal, $\mathrm{A}=\mathrm{A}$-group element, and $\mathrm{X}=\mathrm{C} / \mathrm{N})$ are of special interest because they possess a unique combination of the advantages of both metals and ceramics. Most attention is attracted to the ternary carbide $\mathrm{Cr}_{2} \mathrm{AlC}$ because of its excellent high-temperature oxidation, as well as hot corrosion resistance. Despite lots of publications, up to now the influence of bias voltage on the chemical bonding structure, surface morphology, and mechanical properties of the film is still not well understood. In the current study, $\mathrm{Cr}$-Al-C films were deposited on silicon wafers (100) and Inconel 718 super alloy by dc magnetron sputtering with different substrate bias voltages and investigated using Scanning Electron Microscopy (SEM), X-ray Photoelectron Spectroscopy (XPS), X-ray Diffraction (XRD), Atomic Force Microscopy (AFM), and nanoindentation. Transmission Electron Microscopy (TEM) was used to analyze the correlation between the growth of the films and the coating microstructure. The XPS results confirm the presence of $\mathrm{Cr}_{2} \mathrm{AlC}$ MAX phase due to a negative shift of $0.6-0.9 \mathrm{eV}$ of the Al2p to pure aluminum carbide peak. The XRD results reveal the presence of $\mathrm{Cr}_{2} \mathrm{AlC}$ MAX Phase and carbide phases, as well as intermetallic $\mathrm{AlCr}_{2}$. The film thickness decreases from 8.95 to $6.98 \mu \mathrm{m}$ with increasing bias voltage. The coatings deposited at $90 \mathrm{~V}$ exhibit the lowest roughness $(33 \mathrm{~nm}$ ) and granular size $(76 \mathrm{~nm})$ combined with the highest hardness (15.9 GPa). The ratio of $\mathrm{Al}$ carbide to carbide-like carbon state changes from 0.12 to 0.22 and correlates with the mechanical properties of the coatings. TEM confirms the columnar structure, with a nanocrystalline substructure, of the films.
\end{abstract}

Keywords: XPS; AFM; MAX phase; TEM; chemical bonding; surface morphology

\section{Introduction}

MAX phases are ternary carbides and/or nitrides with the composition form $\mathrm{M}_{n+1} \mathrm{AX}$, where $n$ is 1,2 or 3; $\mathrm{M}$ is an early transition metal; $\mathrm{A}$ is an A-group element from the periodic table of elements; and $X$ is carbon or nitrogen [1]. Since their scientific discovery in the 1960s by Jeitschko et al. [2,3], MAX phases have gained significant attention due to their combination of the merits of metals and ceramics [4,5]. They exhibit high stiffness [6,7], easy machinability [5], self-healing behavior [8], chemical- $[9,10]$, oxidation- $[11,12]$ and hot corrosion resistance $[13,14]$. 
MAX-phase films have been synthesized using different chemical (CVD) and physical (PVD) methods. In 2002, Palmquist et al. [15] deposited $\mathrm{Ti}_{3} \mathrm{SiC}_{2}$ onto single-crystal substrates by Physical Vapour Deposition (PVD). Since then different PVD methods have been used for the deposition of MAX phases, including magnetron sputtering.

Nowadays, the ternary carbide $\mathrm{Cr}_{2} \mathrm{AlC}$ has a great potential for industrial application due to excellent high-temperature oxidation resistance and hot corrosion resistance due to the formation of a protective $\mathrm{Al}_{2} \mathrm{O}_{3}$ layer [16-19]. $\mathrm{Cr}_{2} \mathrm{AlC}$ film has been successfully deposited onto silicon wafers [20], single crystalline oxide [21,22], steel [23], Ni-based superalloy [17,24], and Ti alloy [25]. $\mathrm{Cr}_{2} \mathrm{AlC}$ has been produced using magnetron sputtering, either by sputtering from elemental targets [26] or compound targets [23]. Field et al. [27] deposited $\mathrm{Cr}_{2} \mathrm{AlC}$ coatings using direct current magnetron sputtering (DCMS) and high power impulse magnetron sputtering (HiPIMS).

It is well known that the microstructure and properties of PVD coatings strongly depend on deposition parameters such as deposition temperature, sputtering power, substrate bias, etc. [28]. The deposition temperature needed for the formation of $\mathrm{Cr}_{2} \mathrm{AlC}$ thin films was discussed in different works [13,23,24]. Walter et al. [23] reported the formation of $\mathrm{Cr}_{2} \mathrm{AlC}$ from a compound target at a substrate temperature of $450^{\circ} \mathrm{C}$. Li et al. [24] produced $\mathrm{Cr}_{2} \mathrm{AlC}$ coatings by magnetron sputtering from a bulk $\mathrm{Cr}_{2} \mathrm{AlC}$ target at a substrate temperature range of $370-500{ }^{\circ} \mathrm{C}$. However, Abdulkadhim et al. [13] reported that a higher temperature is required for $\mathrm{Cr}_{2} \mathrm{AlC}$ formation. In a previous publication by Naveed et al. [17], the influence of sputtering power on growth and mechanical properties of $\mathrm{Cr}_{2} \mathrm{AlC}$ was already discussed. It was found that preferential coating growth orientation changes and a slight increase in hardness occurs with increasing sputtering power.

However, despite many studies on magnetron sputtered $\mathrm{Cr}_{2} \mathrm{AlC}$ films $[13,17,23,24,26,27,29-31]$, up to now the effect of bias voltage on the chemical bonding structure, surface morphology, and mechanical properties of film is still not well understood.

The purpose of this work is to study the influence of bias voltage on the properties of $\mathrm{Cr}-\mathrm{Al}-\mathrm{C}$ coatings deposited onto IN718 and silicon wafers (100). The influence of the substrate bias voltage on the coating characteristics, such as chemical bonding structure, surface morphology, and roughness, was investigated using X-ray photoelectron spectroscopy (XPS) and atomic force microscopy (AFM). Mechanical properties were examined by means of nanoindentation. Transmission electron microscopy was used to analyze the correlation between the growth of the films and the coating microstructure.

\section{Experimental Section}

Cr-Al-C coatings were deposited on (100) silicon wafers and Inconel 718 super alloy ( $\mathrm{NiCr} 19 \mathrm{Fe} 19 \mathrm{Nb} 5 \mathrm{Mo} 3$ ), finding its application in gas turbines [32]. Inconel 718 specimens were polished using $\mathrm{SiC}$ paper up to 2400 grade, further cleaned ultrasonically, and dried in air. The coating deposition was performed in a CC800/9 industrial coater from CemeCon AG (Würselen, Germany). Prior to deposition, the specimens were etched under a vacuum at a pressure of $350 \mathrm{MPa}$ for $30 \mathrm{~min}$. Direct current magnetron sputtering was used with a compound target $\left(88 \times 500 \mathrm{~mm}^{2}\right)$ with a Cr:Al:C composition of 2:1:1 supplied by CemeCon AG. The sputtering process was performed in static mode. The deposition temperature was $550^{\circ} \mathrm{C}$ because this temperature is shown in the literature as the lowest temperature, where $\mathrm{Cr}_{2} \mathrm{AlC}$ formation is ensured [13]. The distance between the target and the substrate was $70 \mathrm{~mm}$. Further details of the deposition process parameters for $\mathrm{Cr}-\mathrm{Al}-\mathrm{C}$ coatings are given in Table 1.

Table 1. Deposition parameters of Cr-Al-C coatings.

\begin{tabular}{cc}
\hline Parameter & Value \\
\hline Ar Pressure & $600 \mathrm{MPa}$ \\
Cathode Power & $2.5 \mathrm{KW}$ \\
Deposition Temperature & $560^{\circ} \mathrm{C}$ \\
Bias Voltage & $-60 \mathrm{~V} /-90 \mathrm{~V} /-120 \mathrm{~V}$ \\
Deposition Time & $1 \mathrm{~h}$ \\
\hline
\end{tabular}


A scanning electron microscope (SEM, TESCAN Mira, Prague, Czech Republic) was used to investigate the growth of the films on (100) Si wafers. Crystallographic phases and XRD patterns of the films were identified using a D8 Discover X-ray diffractometer (Bruker AXS, Karlsruhe, Germany) with a grazing incidence $X$-ray diffraction (GIXRD) method at a low incident angle of $9^{\circ}$ with a $\mathrm{Cu} \mathrm{K} \alpha$ source $(\lambda=0.15406 \mathrm{~nm})$ operating at $40 \mathrm{kV}$ and $40 \mathrm{~mA}$.

An ES300 KRATOS spectrometer (Kratos Analytical, Manchester, UK), equipped with an X-ray tube with twin $\mathrm{Mg}$ and $\mathrm{Al}$ anodes, was used for the XPS studies. Prior to the installation of the samples into the spectrometer, their surfaces were cleaned by washing them several times in pure ethanol. Photoelectron spectra were acquired after evacuation to an ultra-high vacuum (UHV, $5 \times 10^{-9}$ mbar). The electron analyzer was calibrated against Au4f7/2 (84.0 eV) and Cu2p2/3 $(932.7 \mathrm{eV})$ photoelectron line positions obtained from $\mathrm{Ar}^{+}$ion cleaned metallic surfaces of copper and gold. Non-monochromated $\mathrm{Mg} \mathrm{K} \alpha$-radiation was used for sample analysis. Due to the conductivity of the samples, the XP-spectra were presented without calibration.

The spectra processing was performed using XPS-Calc software (Boreskov Institute of catalysis, Novosibirsk, Russia) [33]. Doniach-Sunjic asymmetric lineshape was used for the description of the components related to carbide phase in $\mathrm{Cr} 2 \mathrm{p}, \mathrm{Al} 2 \mathrm{p}$, and $\mathrm{C} 1 \mathrm{~s}$ spectra due to the conductive character of this phase. The sample coated at $90 \mathrm{~V}$ bias voltage was characterized by XPS after evacuation to UHV and after $\mathrm{Ar}^{+}$ion etching at $1 \mathrm{keV}$ and $20 \mathrm{~mA}$ for 30, 60, 90 and $120 \mathrm{~min}$. The samples prepared with other bias voltages were characterized after 120 min ion etching.

The surface morphology of the films was analyzed by AFM ("Smena" microscope by NT-MDT, Zelenograd, Russia) operating in contact mode with cantilever NSG 11 Pt (NT-MDT). The AFM observation was supported by TEM methods, using a Hitachi H-800 transmission electron microscope (Hitachi High-Technologies Corp., Tokyo, Japan) with an accelerating voltage of $150 \mathrm{kV}$. Cross-sectional samples were prepared using the focused ion beam (FIB) technique. The selected area diffraction patterns were analyzed using software developed in the Electron Microscopy Lab at Wroclaw University of Technology. In order to determine the mechanical properties (hardness and E-Modulus) of the coatings, nanoindentation tests were carried out using a UNAT nanoindenter (ASMEC GmbH, Radeberg, Germany) with a Berkovich Indenter (three-face pyramid diamond) by means of the Quasi Continuous Stiffness Method (QCSM). A load of $15 \mathrm{mN}$ was used, hence the penetration depth did not exceed $10 \%$ of the total coating thickness in order to neglect the substrate effect $[17,32]$. The load-displacement curves were analyzed using the Oliver Pharr method [34]. For each sample, the mean value of twenty single measurements was calculated.

\section{Results and Discussion}

\subsection{Scanning Electron Microscopy}

The coating growth was analyzed by means of SEM, as shown in Figure 1. The cross-sectional view of the coating deposited at $60 \mathrm{~V}$ shows a collection of dense columns grown on the substrate with an angle of nearly $75^{\circ}$ with respect to the substrate. Surface analysis indicates a feathery structure showing apparent columns of various diameters. According to the Thornton model, this structure could be attributed to Zone-T [35]. With the increase of substrate voltage, a clear change in column growth can be seen. Different growth angles of approximately $56^{\circ}$ and $59^{\circ}$ can be observed for $\mathrm{Cr}$-Al-C during growth at $90 \mathrm{~V}$ and $120 \mathrm{~V}$, respectively. Naveed et al. [17] observed similar columnar structures with certain column orientations relating to the substrate at sputtering powers up to $2.5 \mathrm{~kW}$. 

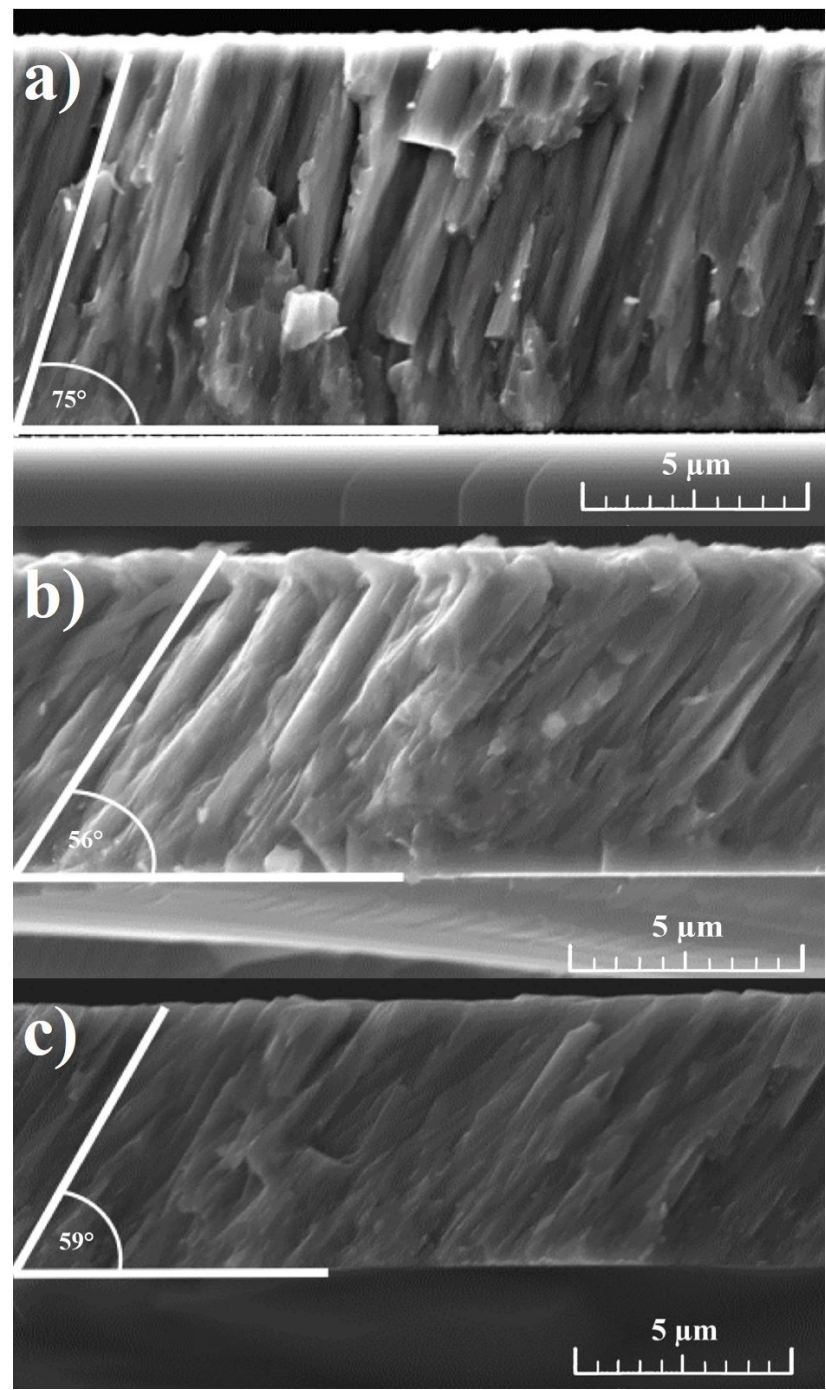

Figure 1. Cross-section SEM images of the $\mathrm{Cr}-\mathrm{Al}-\mathrm{C}$ coatings deposited at various bias voltages (a) $60 \mathrm{~V}$; (b) $90 \mathrm{~V}$; and (c) $120 \mathrm{~V}$.

\section{2. $X R D$}

Representative X-ray diffraction (XRD) patterns of the deposited Cr-Al-C coatings obtained by GIXRD are given in Figure 2. In the range $10^{\circ}-70^{\circ}$, there are two super lattice reflections, (002) and (101), corresponding to the ordered $\mathrm{Cr}_{2} \mathrm{AlC}$ MAX phase $[29,36]$. At around $13.3^{\circ},(002)$ weak reflection for coatings at 60 and $90 \mathrm{~V}$ was found, identifying the presence of the MAX phase [29]. The XRD patterns corresponding to $60 \mathrm{~V}$ and $90 \mathrm{~V}$ are very similar. These two coatings show the $\mathrm{Cr}_{2} \mathrm{AlC}(103)$ as the dominant orientation and a small amount of $(100 / 101)$ of the same phase. The XRD pattern of $120 \mathrm{~V}$ is different to the others. The $\mathrm{Cr}_{2} \mathrm{AlC}$ (103) peak is stronger for $120 \mathrm{~V}$, which can be related to larger grains, higher crystallinity, or more MAX phase. This is in good correlation with the results of Field et al. [27], who showed for DCMS and HiPIMS deposited coatings that $\mathrm{Cr}_{2} \mathrm{AlC}$ (103) reflection was the highest. Furthermore, the coating deposited at $120 \mathrm{~V}$ displays the presence of $\mathrm{Cr}_{7} \mathrm{C}_{3}, \mathrm{AlCr}_{2}$, and $\mathrm{Cr}_{23} \mathrm{C}_{6}$ peaks. 


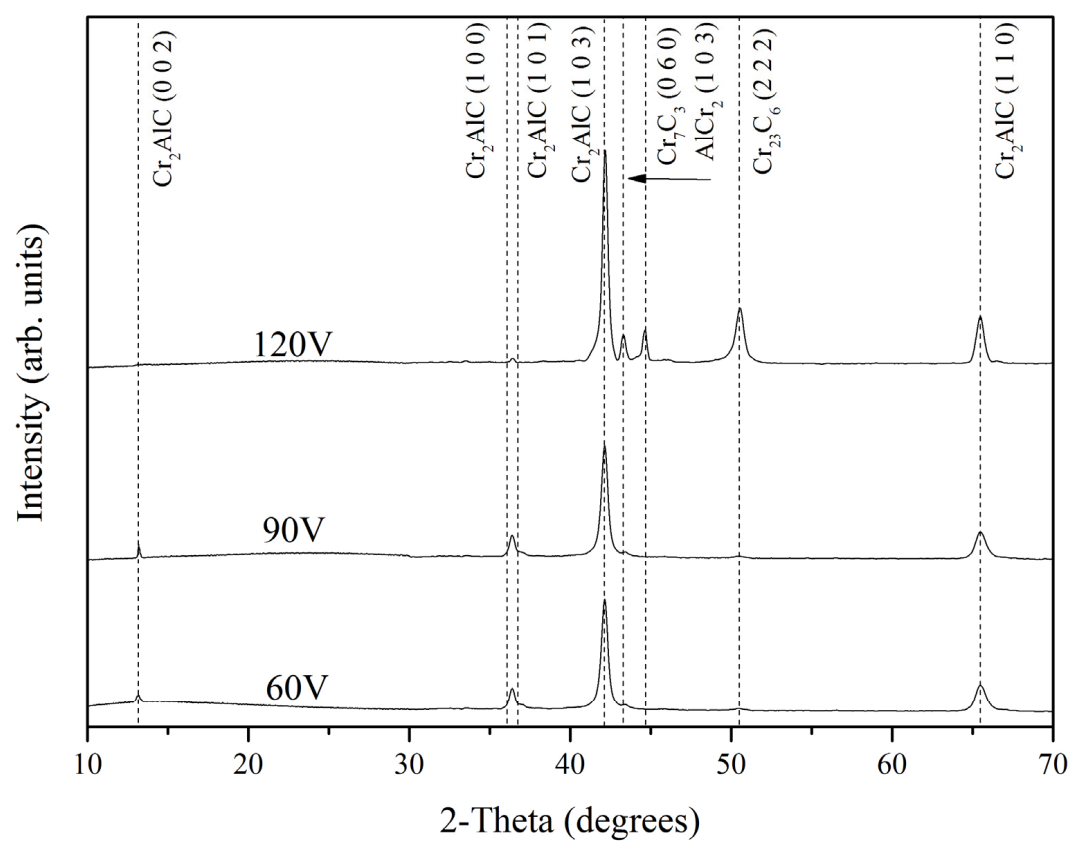

Figure 2. X-ray diffraction (XRD) patterns of the deposited $\mathrm{Cr}-\mathrm{Al}-\mathrm{C}$ coatings.

\subsection{X-ray Photoelectron Spectroscopy}

XPS analysis allows information to be obtained about the chemical structure of the elements on the surface of samples. The samples were exposed to air prior to the XPS measurements. Therefore, the initial surface of all samples was oxidized and strongly contaminated. Survey spectra revealed $\mathrm{Cr}, \mathrm{Al}, \mathrm{C}$ and O peaks, and a carbon content of more than $50 \%$ was measured on the surface (Figure $3 a$ ). $\mathrm{Cr}$ as well as $\mathrm{Al}$ concentrations on the untreated surface were observed at about $5 \%$. The coating deposited at $90 \mathrm{~V}$ was measured after 30, 60, 90 and 120 min of argon ion etching $\left(\mathrm{Ar}^{+}\right.$etching rate: $2 \AA / \mathrm{min}$ ) in order to study the chemical composition of the surface layers. Figure $3 \mathrm{~b}$ shows the atomic concentration of the elements versus etching time.

Argon etching led to a decrease of $\mathrm{C}$ and $\mathrm{O}$ and to an increase of $\mathrm{Cr}$ and $\mathrm{Al}$ concentration due to the removal of contaminated and oxidized layers on the surface. The composition reached a constant value after 60-90 min of argon etching. It is noticed that after $120 \mathrm{~min}$ of etching, oxygen still remained at approximately $20 \%$. It is assumed that this amount of oxygen was incorporated into the coatings during deposition. The analysis of the deposition process reveals that the most likely source of oxygen contamination may be residual oxygen in the deposition chamber. The oxygen incorporation in the structure of $\mathrm{M}_{2} \mathrm{AlC}$ phases is well known [31,37]; however in our case the concentration is higher than expected.

Note that the initial surface was depleted with chromium; the $\mathrm{Al} / \mathrm{Cr}$ ratio was about 1 . The chromium concentration sharply increased in the first $30 \mathrm{~min}$ of etching and slightly changed during further etching, while the aluminum concentration remained almost constant. Thus, the inner layers (6-24 nm depth) were depleted with aluminum. The upper limit of the Al/Cr ratio (Figure 3b) was estimated to be less than 0.35 , which was substantially lower than the specified value of 0.5 . The origin of such a low $\mathrm{Al} / \mathrm{Cr}$ ratio obtained from XPS is discussed below (see the description of Al2p $+\mathrm{Cr} 3 \mathrm{~s}$ lines presented on Figure 4). Thus, all samples were substantially depleted with aluminum in the subsurface layers. The amount of oxygen on the cleaned surfaces increased with the decrease in substrate bias from 120 to $60 \mathrm{~V}$.

Typical high resolution XPS spectra of Cr2p, Al2p, and C1s core levels of coatings prepared at different bias voltages are presented on Figure $4 a-c$. Etching of the surface for $120 \mathrm{~min}$ led to almost complete removal of oxidized $\mathrm{Cr}^{3+}$ species and carbon contaminants. 

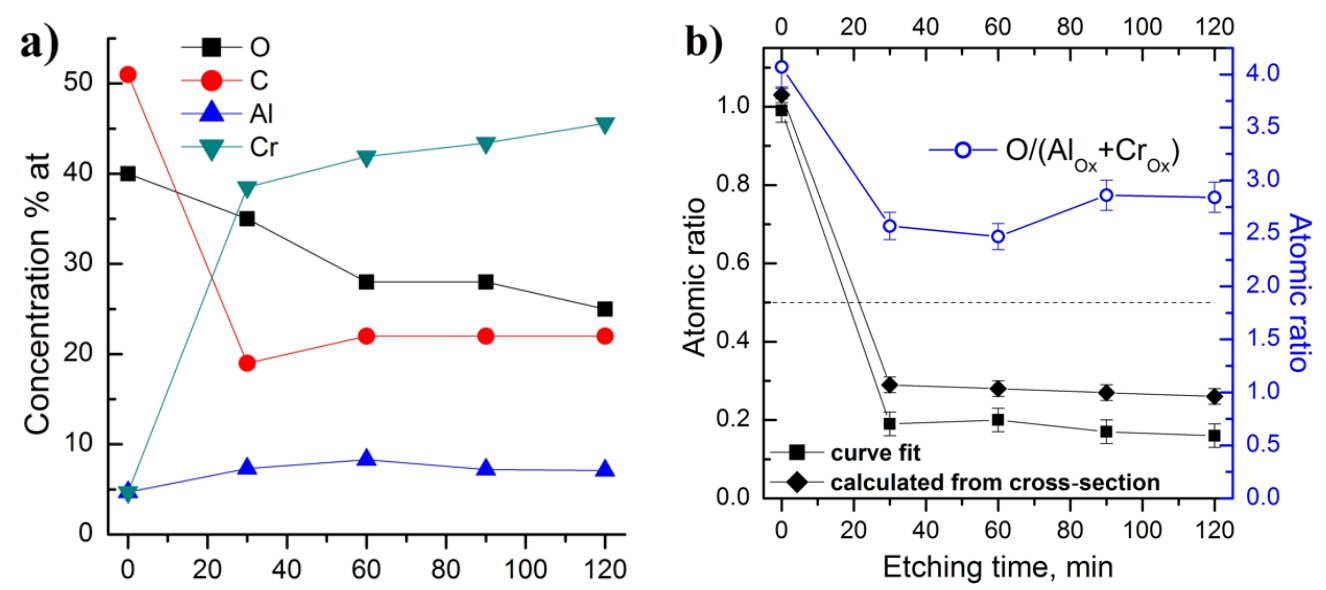

Figure 3. (a) Atomic composition at the surface; (b) $\mathrm{O} /\left(\mathrm{Al}_{\mathrm{Ox}}+\mathrm{Cr}_{\mathrm{Ox}}\right)$ and $\mathrm{Al} / \mathrm{Cr}$ atomic ratios for $\mathrm{Cr}-\mathrm{Al}-\mathrm{C}$ coating at $90 \mathrm{~V}$ as a function of $\mathrm{Ar}^{+}$etching time obtained two different ways.

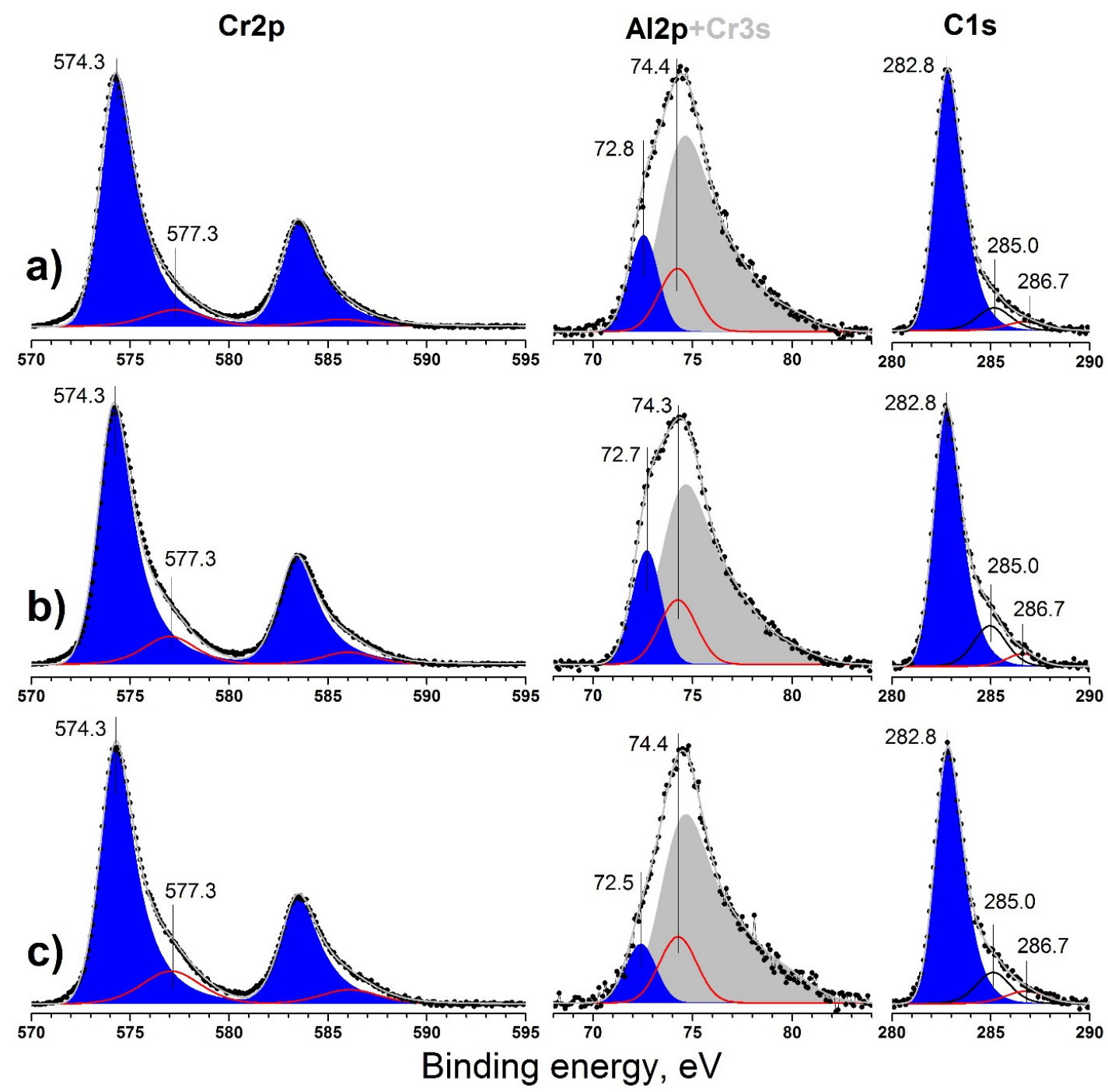

Figure 4. Cr2p, Al2p, and C1s XP-spectra obtained for Cr-Al-C films at (a) $120 \mathrm{~V}$; (b) $90 \mathrm{~V}$; and (c) $60 \mathrm{~V}$ after $\mathrm{Ar}^{+}$ion etching for $120 \mathrm{~min}$. 
The carbon valence state represented mainly by the peak at 282.8 is typical for carbide-like carbon in all cases, i.e., typical for the $\mathrm{Cr}-\mathrm{C}$ bond [38]. Higher than typical values for $\mathrm{Al}_{4} \mathrm{C}_{3}(282.2 \mathrm{eV})$ indicate the absence of a discrete aluminum carbide phase [39]. Only minor additional components were observed at 285.0 and $286.6 \mathrm{eV}$, which corresponds to elementary carbon ( $\mathrm{C}-\mathrm{C}$ bonds) and oxidized carbon species $(\mathrm{C}-\mathrm{O})$. They were probably formed due to the decomposition of carbide phases into pure elements under ion beam influence (Ar ion damage [40]) and the subsequent removal of the decomposition products [41,42]. Thus, a steady-state concentration of elementary carbon species was observed.

Chromium was represented by two states with binding energies; $(B E)=574.3$ and $577.3 \mathrm{eV}$. Minor components at $577.3 \mathrm{eV}$ corresponding to $\mathrm{Cr}_{2} \mathrm{O}_{3}$ were observed [43]. The main asymmetric component at $574.3 \mathrm{eV}$ corresponds to chromium in carbide phase [44] or in metallic $\mathrm{Cr}$ [38]. Similar XPS results were presented by Zamulaeva et al. for $\mathrm{Cr}_{2} \mathrm{AlC}$ prepared using pulsed electrospark deposition (PED) [45]. Furthermore, both peaks are situated in the same position for all coatings, and no chemical shift could be discerned.

The minor Cr3s photoelectron line overlaps with the Al2p main photoelectron line of aluminum. The estimation of Al2p contribution to this spectrum is possible via two ways. Theoretical Al2p contribution can be estimated using the Cr2p photoelectron spectra and Scofield cross-sections [46] of the $3 \mathrm{~s}$ and $2 \mathrm{p}$ core-levels of chromium for the calculation of the $\mathrm{Cr} 3 \mathrm{~s}$ line intensity. Thus, the theoretical $\mathrm{Al} / \mathrm{Cr}$ ratio could be obtained. The most probable experimental $\mathrm{Al} / \mathrm{Cr}$ ratio can be estimated via the curve of best fit of the experimental spectrum from the total areas of the peaks at 72.7 and $74.4 \mathrm{eV}$ in the Al2p $+\mathrm{Cr} 3 \mathrm{~s}$ on Figure 4 using binding energy and the shape of $\mathrm{Cr} 3$ s taken from $[43,47,48]$. The $\mathrm{Al} / \mathrm{Cr}$ ratios obtained each way are presented in Figure $3 \mathrm{~b}$. The $\mathrm{Al} / \mathrm{Cr}$ ratio was calculated to be about 0.3 using the theoretical approach and about 0.2 using curve fitting of the experimental spectra, which were both lower than the specified value 0.5 .

Aluminum was much more oxidized compared to chromium due to its more metallic chemical properties, as obvious from the intensity of the peak at 74.3-74.4 corresponding to $\mathrm{Al}_{2} \mathrm{O}_{3}[49,50]$. The accuracy of the Al2p + Cr3s photoelectron line fitting is confirmed by the quotient of the total oxygen amount and the oxidized $\mathrm{Al}+\mathrm{Cr}$ species (doublet peak at $577.3 \mathrm{eV}$ in $\mathrm{Cr} 2 \mathrm{p}$ and peak at 74.4 in $\mathrm{Al} 2 \mathrm{p}+\mathrm{Cr} 3 \mathrm{~s})$, which is close to 3 and presented in Figure 5b. Thus, these peaks in the Cr2p and $\mathrm{Al} 2 \mathrm{p}+\mathrm{Cr} 3 \mathrm{~s}$ lines correspond to $\mathrm{Cr}_{2} \mathrm{O}_{3}$ and $\mathrm{Al}_{2} \mathrm{O}_{3}$, respectively.

The peak at 72.8-72.5 eV formally corresponds to metallic aluminum, which has a binding energy of about 72.6-72.8 eV [39,51]. Aluminum carbide is characterized by a higher binding energy of Al2p core level $73.4 \mathrm{eV}$ [39]. Thus, taking into account the rather high reactivity of aluminum towards carbon [39], we attribute this state to $\mathrm{Cr}_{2} \mathrm{AlC}$. The negative shift $0.6-0.9 \mathrm{eV}$ relative to pure aluminum carbide can be explained with more metallic $\mathrm{Al}-\mathrm{C}$ bonds in $\mathrm{Cr}_{2} \mathrm{AlC}$ phase compared to $\mathrm{Al}_{4} \mathrm{C}_{3}$. Zhang et al. observed a similar negative shift of the Al2p core level for $\mathrm{Ti}_{2} \mathrm{AlN}$ phase compared to pure AlN. Thus, such a shift could be used as indicator of MAX phase formation [51,52]. In the current study, the XPS results could confirm the formation of a $\mathrm{Cr}_{2} \mathrm{AlC}$ MAX phase, and these results are in good agreement with the XRD measurements.

The $\mathrm{Cr}$ and $\mathrm{Al}$ carbide states standardized on carbide-like $\mathrm{C}$ reached a constant value after 30 min of ion etching, while total carbide-like $C$ concentration reached a constant value only after $60 \mathrm{~min}$ of ion etching (Figure 5a). Thus, despite the removal of carbon contaminants and oxidized species, the carbide phase composition is constant in the topmost $\sim 24 \mathrm{~nm}$; however, this phase is deplete of aluminum and corresponds to $\mathrm{Cr} 2 \mathrm{Al} \cdot \mathrm{A} \cdot 25 \mathrm{C} 1$ stoichiometry in the case of the $\mathrm{Cr}-\mathrm{Al}-\mathrm{C}$ coating at $90 \mathrm{~V}$ (Figure 5a). Taking into account the oxidation of the surfaces with oxygen traces during ion etching, the initial "non-oxidized" surface composition was estimated to correspond to the Cr2:Al0.6-0.7:C1 stoichiometry under this assumption.

Moreover, the $\mathrm{Cr}$ carbide to carbide-like $\mathrm{C}$ state ratio was very stable, independent of the bias voltage (Figure $5 b$ ), and equal to 2.03-2.1, while the Al non-oxidized carbide state to carbide-like C state varied from 0.12 to 0.22 . 

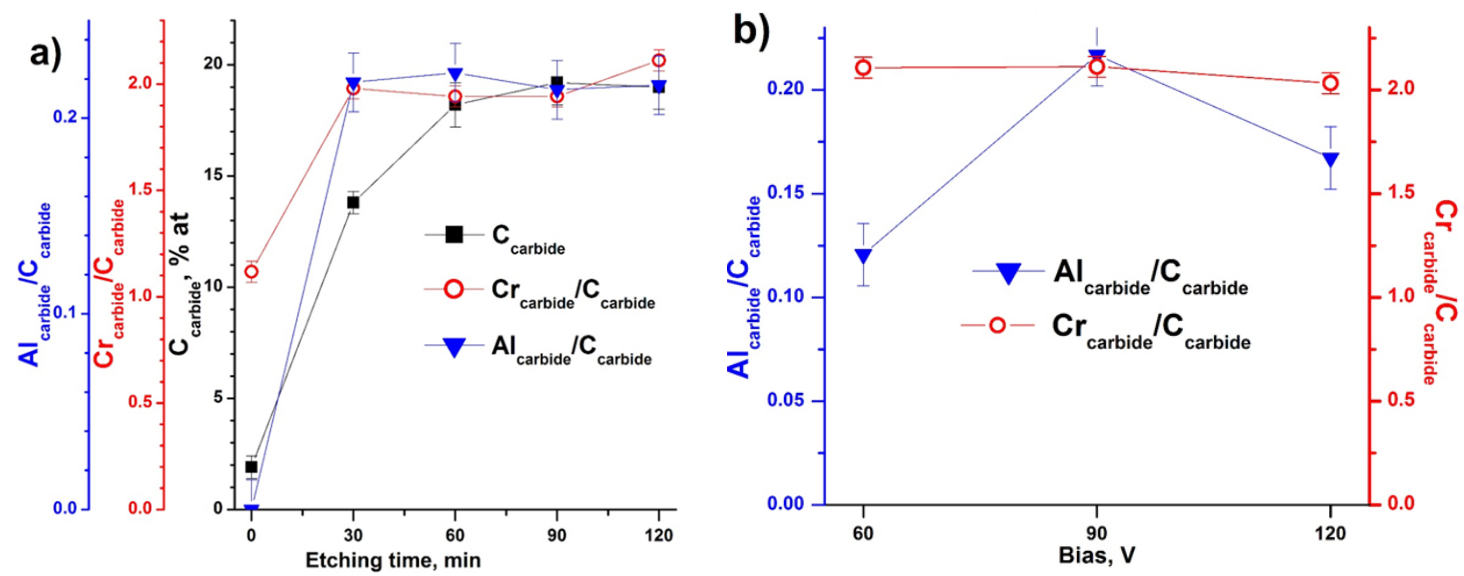

Figure 5. (a) Atomic concentration of carbide-like carbon in relation to all elements; atomic ratio of chromium carbide $(574.3 \mathrm{eV})$ and aluminum carbide $(72.5-72.8 \mathrm{eV})$ states to carbide like carbon (282.8 eV); and $\mathrm{Ar}^{+}$etching time obtained for $\mathrm{Cr}-\mathrm{Al}-\mathrm{C}$ at $90 \mathrm{~V}$; (b) $\mathrm{Cr}_{\text {carbide }} / \mathrm{C}_{\text {carbide }}$ and $\mathrm{Al}_{\text {carbide }} / \mathrm{C}_{\text {carbide }}$ ratios obtained for all samples after $120 \mathrm{~min}$ of $\mathrm{Ar}^{+}$ion etching vs. bias voltage.

\subsection{Atomic Force Microscopy}

AFM gives information about the morphological properties of films. The main characteristics of Cr-Al-C coatings like thickness, surface roughness, and granular size are listed in Table 2. Thickness, as a function of bias voltage, shows an inverse relationship with the bias. The film thickness reduces from 8.95 to $6.98 \mu \mathrm{m}$, which can be related to the notable sputtering off of the film (re-sputtering) $[53,54]$.

Table 2. Effect of the bias voltage on the morphological properties of the films.

\begin{tabular}{cccc}
\hline Bias Voltage $(\mathbf{V})$ & Thickness $(\boldsymbol{\mu m})$ & RMS $(\mathbf{n m})$ & Granular Size $(\mathbf{n m})$ \\
\hline 60 & 8.95 & 100 & 179 \\
90 & 7.16 & 33 & 76 \\
120 & 6.98 & 60 & 134 \\
\hline
\end{tabular}

During increasing bias voltage, the incident ion energy rises and, therefore, more atoms from the growing coatings will be re-sputtered $[55,56]$. These results are in good correlation with the literature [53,57-59]. However, Jiang et al. showed that, at a low bias voltage (till $50 \mathrm{~V}$ ), the thickness can increase with rising bias until the ion current density is saturated [54].

The surface morphologies of the coated silicon substrates were examined by the AFM method and shown in Figure 6. All films have a granular structure with visible agglomerated grains. The Cr-Al-C coating deposited at $60 \mathrm{~V}$ exhibits the morphology with the highest RMS (root-mean-square). As the substrate bias changes from 60 to $90 \mathrm{~V}$, the structure changes from irregular to rectangular particulates with random alignment and the roughness sharply decreases to $33 \mathrm{~nm}$, indicating a surface-smoothing phenomenon.

The lateral force map for the sample deposited at $90 \mathrm{~V}$ with the pronounced superstructure of the films is presented in Figure 6d. A step-line structure is evident, and its edges are visible. At $120 \mathrm{~V}$, the film became again rougher with a roughness of about $60 \mathrm{~nm}$ (Figure $6 \mathrm{c}$ ). The increase in roughness with rising bias voltage can be explained by higher ion energy [60,61].

The average granular size was obtained using atomic force microscopy. Similar to the roughness, the granular size significantly decreases as the bias increases from $60 \mathrm{~V}$ to $90 \mathrm{~V}$ and then rises during a further increase to $120 \mathrm{~V}$. 

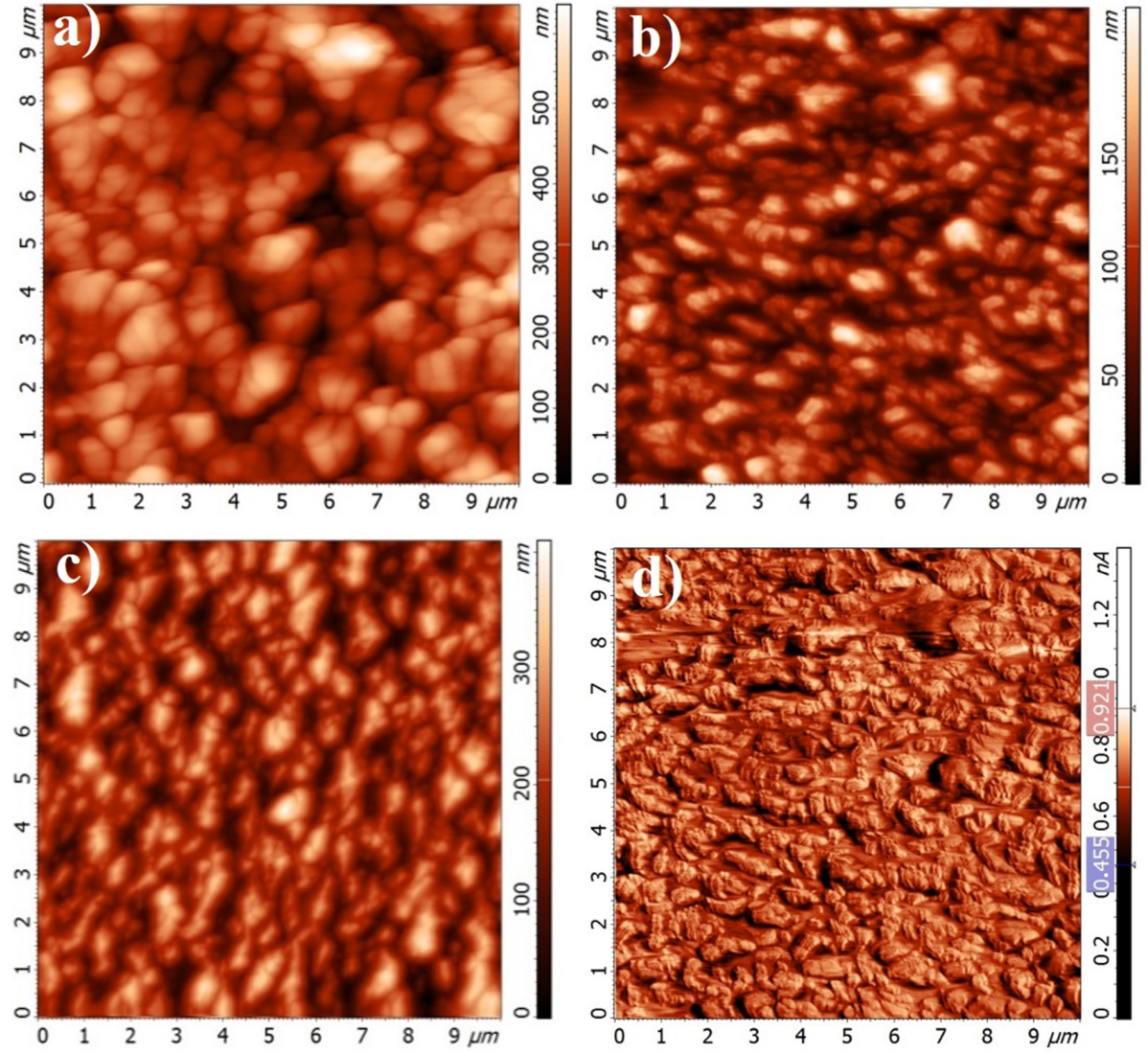

Figure 6. Atomic force microscopy (AFM) topography images of Cr-Al-C films on a $\mathrm{Si}$ (100) wafer at (a) $60 \mathrm{~V}$; (b) $90 \mathrm{~V}$; (c) and $120 \mathrm{~V}$; (d) A lateral force map at $90 \mathrm{~V}$.

Reduction of granular size can also be related to a modification of the superficial morphology by argon ion bombardment, increasing the energy associated with the atoms on the substrate surface and/or the growing coating surface [62]. In addition, Lee et al. [63] reported that applied DC bias may cause an increase in the point defects in the film's structure, increasing compressive residual stress and reducing the grain size. However, as mentioned above, when the bias voltage increases, the ion energy increases, resulting in higher adatom mobility. High energy promotes diffusion as well as grain boundary migration that might cause increasing granular size $[60,64]$. Similar results were also reported by Gangopadhyay et al. [53] and Zhang et al. [65]. As available from Table 2, the first increase in bias voltage results in a decreasing granular size, while a further increase in bias voltage leads to an increase in granular size. Therefore, in the literature, both effects were discussed contradictorily. Thus, a superposition of different effects takes place. The problem of whether higher adatom mobility, higher ion energy, and more defects result in smaller or larger granular size has still not been solved [53,65].

\subsection{Transmission Electron Microscopy}

Cross-sectional TEM samples of the $\mathrm{Cr}_{2} \mathrm{AlC}$ film deposited at $90 \mathrm{~V}$ were analyzed by means of TEM to understand the coating growth. The coating layer exhibits a columnar polycrystalline growth structure consisting of 120-250 nm width columns (Figure 7a). The selective area electron diffraction taken from a 3- $\mu \mathrm{m}$ diameter circle shows a textured coating with preferential columnar orientation. $\mathrm{Cr}_{2} \mathrm{AlC}$ phase was recognized and the $\mathrm{Cr}_{2} \mathrm{AlC}$ planes $(012)\left(d_{012}=0,2311 \mathrm{~nm}\right),(013)\left(d_{013}=0,2143 \mathrm{~nm}\right)$, $(016)\left(d_{016}=0,1619 \mathrm{~nm}\right)$, and $(008)\left(d_{008}=0,1346 \mathrm{~nm}\right)$ were detected. The coating is visibly textured. The angle measurement of the most varied diffraction spots in the same interplanar distance showed that most of the grains are oriented in $\pm 15^{\circ}$ angle to the main growth axis. 


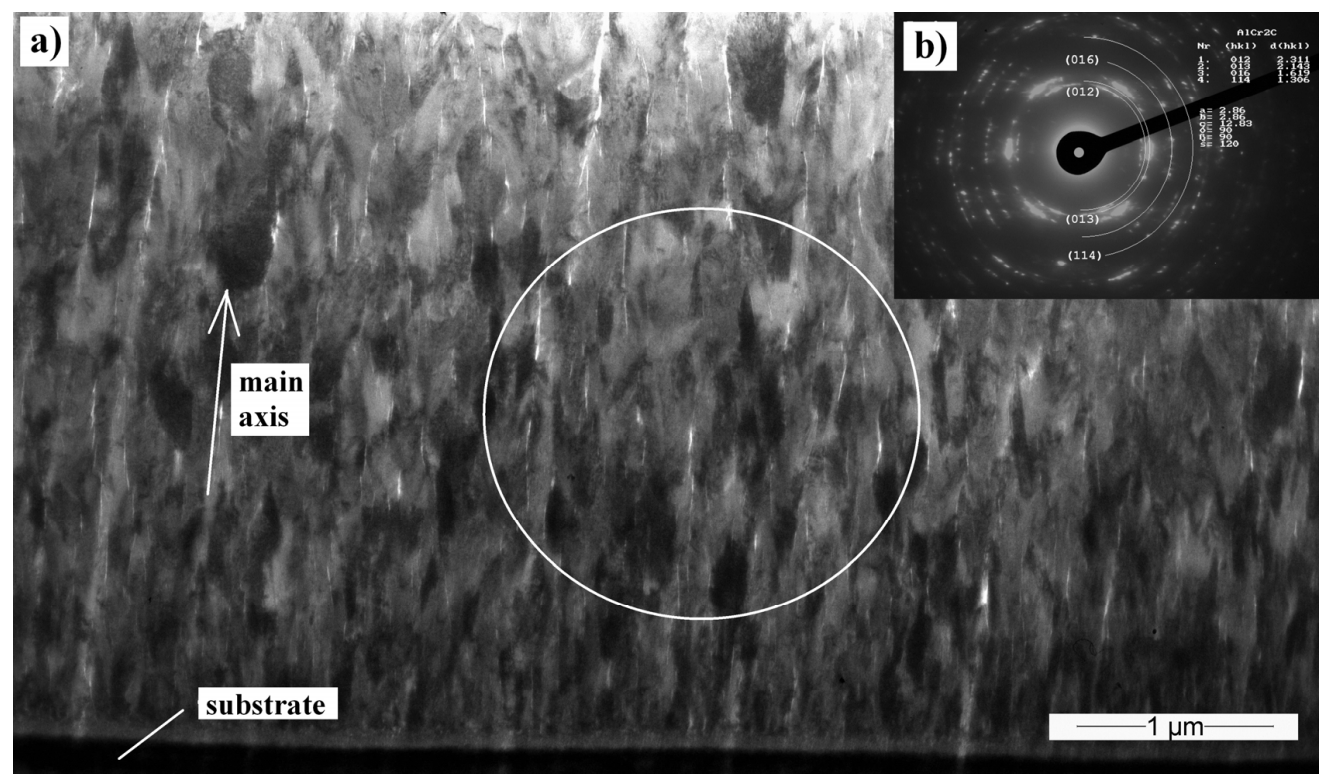

Figure 7. (a) Transmission electron microscopy (TEM) cross-sectional bright-field (BF) image of the $\mathrm{Cr}_{2} \mathrm{AlC}$ coating, deposited at $90 \mathrm{~V}$; (b) Selective area electron diffraction (SAED) obtained in the place marked by the circle.

The substrate-coating interface region shows the presence of two layers marked with the numbers 1 and 2 in Figure 8. An amorphous or nanocrystalline layer marked with number 1 has about a $50-60 \mathrm{~nm}$ thickness. Between the amorphous region and the columnar crystal, a 100-120 nm nanocrystalline layer exists. In this region, the beam is strongly dispersed but has not created a circular polycrystalline pattern. It is possible to observe individual crystalline reflections, but the pattern has the attributes of an amorphous or nanocrystalline structure.

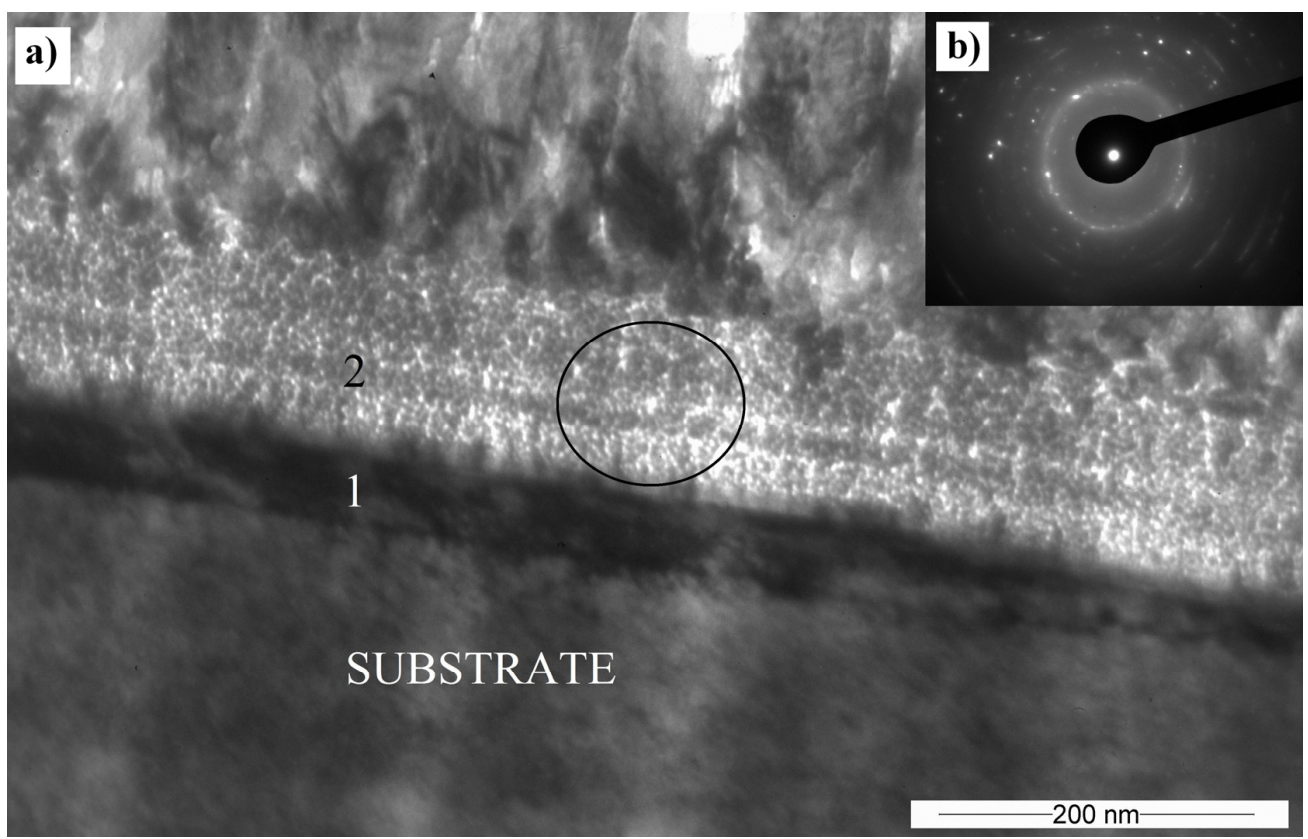

Figure 8. (a) TEM cross-sectional BF image of the $\mathrm{Cr}_{2} \mathrm{AlC}$ coating interface, deposited at $90 \mathrm{~V}$ (1; substrate part of interface, 2; coating part of interface); (b) Selective area electron diffraction (SAED) obtained in the place marked by the circle. 
The diffraction taken in a single grain confirms the presence of $\mathrm{Cr}_{2} \mathrm{AlC}$ phase (Figure 9a). The selected area electron diffraction reveals blurred fuzzy streaks and extra diffraction spots along the direction [016] (Figure 9b). They can be caused by the formation of a superlattice structure inside the $\mathrm{Cr}_{2} \mathrm{AlC}$ grain, ordered stacking faults, or another long-period ordered crystal arrangement. This theory corresponds to the bright-field image, showing an oriented substructure inside the $\mathrm{Cr}_{2} \mathrm{AlC}$ grain (Figure 9a). Further results of the TEM analysis of the crystal growth will be published in the near future.

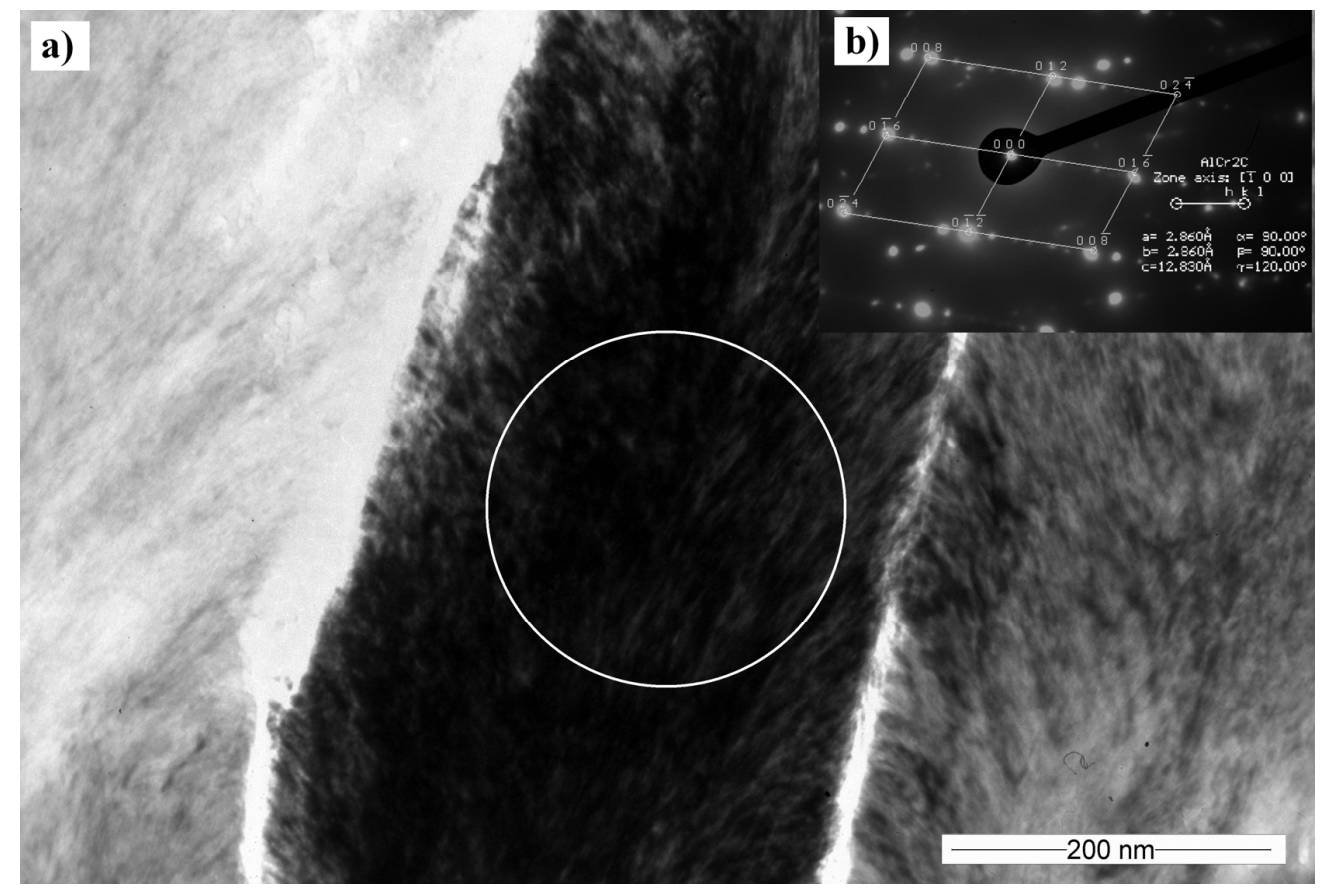

Figure 9. (a) TEM cross-sectional BF image of the single $\mathrm{Cr}_{2} \mathrm{AlC}$ crystal on the top layer of the coating, deposited at $90 \mathrm{~V}$; (b) Selective area electron diffraction (SAED) obtained in the place marked by the circle.

\subsection{Nanoindentation}

The hardness $(H)$, elastic modulus $(E)$, and the $H / E$ and $H^{3} / E^{2}$ ratios of the coatings were obtained using a nanoindenter. The results had shown that the mechanical properties of the coating were influenced by the bias values (Table 3). The hardness and E-modulus values rapidly increased from 8.8 to $15.8 \mathrm{GPa}$ and from 223.4 to $307.7 \mathrm{GPa}$, respectively, when bias rose from $60 \mathrm{~V}$ to $90 \mathrm{~V}$. By further increasing the bias voltage up to $120 \mathrm{~V}, H$ and $E$ were decreased. The $H / E$ and $H^{3} / E^{2}$ values possessed maximums of 0.042 and 0.052 , obtained at a bias voltage of $90 \mathrm{~V}$. High $H / E$ and $H^{3} / E^{2}$ values mean larger elastic strain to failure and higher fracture toughness [66]. The high hardness at $90 \mathrm{~V}$ is probably due to the reduction in granular size caused by the ionic bombardment [62]. Consequently, this enhancement of the mechanical properties with the increase in the applied bias voltage is caused by a blockage for the displacement of the cracks, and thus the energy necessary for the motion of cracks through the coating increases [67]. As previously reported in the literature, an increase in substrate bias raises the level of compressive residual stresses due to an increasing number of impinging ions onto the substrate as well as higher ion current density $[68,69]$. The XPS results show a change in the ratio of $\mathrm{Al}$ carbide state to carbide-like $\mathrm{C}$ state, determining the mechanical properties of the films. This statement needs further investigation and more detailed analysis. The nanoindentation results are consistent with the previous work of the authors [17], with hardness values in the range between 11 and $14 \mathrm{GPa}$ at various sputtering powers as well as with further investigations about $\mathrm{Cr}_{2} \mathrm{AlC}[6,25]$. Schneider et al. [6] measured the hardness value of $\mathrm{Cr}_{2} \mathrm{AlC}$ as $13 \pm 2 \mathrm{GPa}$. Zamulaeva et al. [25] reported a hardness of $15.4 \mathrm{GPa}$ and an elastic modulus of $288 \mathrm{GPa}$ for coatings produced using 
pulsed electrospark deposition (PED). These hardness values are rather low in comparison to the nanoindentation data of $\mathrm{Ti}_{2} \mathrm{AlC}$ [70] and $\mathrm{Ti}_{3} \mathrm{AlC}_{2}$ [71] and are similar to $\mathrm{V}_{2} \mathrm{AlC}$ coatings [72,73] prepared using magnetron sputtering. Furthermore, the hardness values presented above are significantly higher than those for bulk MAX phases, which are typically 2-4 GPa [1]. This increase could be explained by the Hall-Petch's effect [74], wherein the strength of materials is inversely proportional to the square of the crystalline size before a decreased threshold value. Due to the rapid cooling during PVD vapor condensation, the coatings developed nanocrystalline structure, which can be attributed to the better mechanical properties of coatings, compared to bulk material, and confirmed for different MAX phase coatings $[6,72,73]$.

Table 3. Effect of the bias voltage on mechanical properties of the coatings.

\begin{tabular}{ccccc}
\hline Bias (V) & Hardness (GPa) & E-Modulus (GPa) & $\boldsymbol{H} / \boldsymbol{E}$ & $\boldsymbol{H}^{\mathbf{3}} / \boldsymbol{E}^{\mathbf{2}}$ \\
\hline 60 & $8.8 \pm 0.9$ & $223 \pm 20$ & 0.014 & 0.039 \\
90 & $15.9 \pm 3.2$ & $308 \pm 73$ & 0.042 & 0.052 \\
120 & $10.3 \pm 0.5$ & $257 \pm 14$ & 0.017 & 0.040 \\
\hline
\end{tabular}

\section{Conclusions}

The chemical bonding structure, surface morphology, roughness, and mechanical properties of $\mathrm{Cr}-\mathrm{Al}-\mathrm{C}$ thin films deposited at different substrate bias voltages by direct current magnetron sputtering were studied. X-ray photoelectron spectroscopy (XPS) results reveal an unusual negative shift of $0.6-0.9 \mathrm{eV}$ of the Al2p peak relative to pure aluminum carbide. The predominantly metallic $\mathrm{Al}-\mathrm{C}$ bonds can explain this shift in $\mathrm{Cr}_{2} \mathrm{AlC}$ phase, which can be used as indicator for $\mathrm{Cr}_{2} \mathrm{AlC}$ MAX phase formation. These results can be confirmed by means of XRD measurements. The film thickness reduces from 8.95 to $6.98 \mu \mathrm{m}$ due to re-sputtering. Granular size and roughness were obtained using atomic force microscopy (AFM), with the applied substrate bias changing from 60 to $90 \mathrm{~V}$ the roughness decreases and subsequently increases due to the further rise of the substrate bias to $120 \mathrm{~V}$. Transmission electron microscopy (TEM) reveals a columnar structure with a nanocrystalline substructure in all the films and confirms the granular size determined by means of AFM. Nanoindentation shows that hardness increases significantly with the increase of bias voltage from 60 to $90 \mathrm{~V}$ and then decreases for $120 \mathrm{~V}$. This trend of hardness can be explained with a change in granular size as well as the level of compressive residual stresses due to ionic bombardment. XPS shows a change in the ratio of Al carbide to carbide-like $C$ state (from 0.12 to 0.22 ), which affects significantly the mechanical properties of the coatings. Hence, more detailed investigations on this topic are planned for the near future.

Acknowledgments: The authors are thankful to Florian Pyczak and Daniel Laipple (Helmholtz-Center, Geesthacht) for the FIB specimen preparation.

Author Contributions: Aleksei Obrosov carried out the deposition process with the help of Muhammad Naveed. Aleksei Obrosov analyzed the results and prepared the paper. Roman Gulyaev carried out XPS analysis and described the results. Marcus Ratzke provided AFM results. Andrzej Zak and Wlodzimierz Dudzinski provided TEM investigations and described the results. Sabine Weiß revised the manuscript and directed the work.

Conflicts of Interest: The authors declare no conflict of interest.

\section{References}

1. Barsoum, M.W. The $\mathrm{M}_{n+1} \mathrm{AX}$ n phases: A new class of solids: Thermodynamically stable nanolaminates. Prog. Solid State Chem. 2000, 28, 201-281. [CrossRef]

2. Jeitschko, W.; Nowotny, H.; Benesovsky, F. Ti2AlN, eine stickstoffhaltige H-Phase. Monatshefte Chem. Verwandte Teile And. Wiss. 1963, 94, 1198-1200. [CrossRef]

3. Jeitschko, W.; Nowotny, H.; Benesovsky, F. Kohlenstoffhaltige ternäre Verbindungen (H-Phase). Monatshefte Chem. Verwandte Teile And. Wiss. 1963, 94, 672-676. [CrossRef] 
4. Lin, Z.; Zhou, Y.; Li, M. Synthesis, Microstructure, and Property of $\mathrm{Cr}_{2}$ AlC. J. Mater. Sci. Technol. 2007, 23, 721-746.

5. Eklund, P.; Beckers, M.; Jansson, U.; Högberg, H.; Hultman, L. The $\mathrm{M}_{n+1} \mathrm{AX}_{n}$ phases: Materials science and thin-film processing. Thin Solid Films 2010, 518, 1851-1878. [CrossRef]

6. Schneider, J.M.; Sigumonrong, D.; Music, D.; Walter, C.; Emmerlich, J.; Iskandar, R.; Mayer, J. Elastic properties of $\mathrm{Cr}_{2} \mathrm{AlC}$ thin films probed by nanoindentation and ab initio molecular dynamics. Scr. Mater. 2007, 57, 1137-1140. [CrossRef]

7. Hettinger, J.D.; Lofland, S.E.; Finkel, P.; Meehan, T.; Palma, J.; Harrell, K.; Gupta, S.; Ganguly, A.; El-Raghy, T.; Barsoum, M.W. Electrical transport, thermal transport, and elastic properties of $\mathrm{M} 2 \mathrm{AlC}(\mathrm{M}=\mathrm{Ti}, \mathrm{Cr}, \mathrm{Nb}$, and $\mathrm{V})$. Phys. Rev. B 2005, 72, 115120. [CrossRef]

8. Song, G.M.; Pei, Y.T.; Sloof, W.G.; Li, S.B.; de Hosson, J.T.M.; van de Zwaag, S. Oxidation-induced crack healing in $\mathrm{Ti}_{3} \mathrm{AlC}_{2}$ ceramics. Scr. Mater. 2008, 58, 13-16. [CrossRef]

9. Xie, J.; Wang, X.; Li, A.; Li, F.; Zhou, Y. Corrosion behavior of selected $\mathrm{M}_{n+1} \mathrm{AX}_{n}$ phases in hot concentrated $\mathrm{HCl}$ solution: Effect of A element and MX layer. Corros. Sci. 2012, 60, 129-135. [CrossRef]

10. Lin, Z.J.; Li, M.S.; Wang, J.Y.; Zhou, Y.C. High-temperature oxidation and hot corrosion of $\mathrm{Cr}_{2} \mathrm{AlC}_{\text {. Acta Mater. }}$ 2007, 55, 6182-6191. [CrossRef]

11. Hajas, D.E.; Baben, M.; Hallstedt, B.; Iskandar, R.; Mayer, J.; Schneider, J.M. Oxidation of $\mathrm{Cr}_{2} \mathrm{AlC}_{\text {coatings in }}$ the temperature range of 1230 to $1410{ }^{\circ} \mathrm{C}$. Surf. Coat. Technol. 2011, 206, 591-598. [CrossRef]

12. Wang, X.H.; Zhou, Y.C. High-Temperature Oxidation Behavior of $\mathrm{Ti}_{2} \mathrm{AlC}$ in Air. Oxid. Met. 2003, 59, $303-320$. [CrossRef]

13. Abdulkadhim, A.; Baben, M.; Takahashi, T.; Schnabel, V.; Hans, M.; Polzer, C.; Polcik, P.; Schneider, J.M. Crystallization kinetics of amorphous $\mathrm{Cr}_{2} \mathrm{AlC}$ thin films. Surf. Coat. Technol. 2011, 206, 599-603. [CrossRef]

14. Li, J.J.; Li, M.S.; Xiang, H.M.; Lu, X.P.; Zhou, Y.C. Short-term oxidation resistance and degradation of $\mathrm{Cr}_{2} \mathrm{AlC}$ coating on M38G superalloy at 900-1100 ${ }^{\circ}$ C. Corros. Sci. 2011, 53, 3813-3820. [CrossRef]

15. Palmquist, J.-P.; Jansson, U.; Seppänen, T.; Persson, P.U.A.; Birch, J.; Hultman, L.; Isberg, P. Magnetron sputtered epitaxial single-phase $\mathrm{Ti}_{3} \mathrm{SiC}_{2}$ thin films. Appl. Phys. Lett. 2002, 81, 835-837. [CrossRef]

16. Tian, W.; Wang, P.; Kan, Y.; Zhang, G. Oxidation behavior of $\mathrm{Cr}_{2} \mathrm{AlC}$ ceramics at 1100 and $1250{ }^{\circ} \mathrm{C}$. J. Mater. Sci. 2008, 43, 2785-2791. [CrossRef]

17. Naveed, M.; Obrosov, A.; Zak, A.; Dudzinski, W.; Volinsky, A.A.; Weiß, S. Sputtering Power Effects on Growth and Mechanical Properties of $\mathrm{Cr}_{2}$ AlC MAX Phase Coatings. Metals 2016, 6, 265. [CrossRef]

18. Lee, D.B.; Nguyen, T.D. Cyclic oxidation of $\mathrm{Cr}_{2} \mathrm{AlC}$ between 1000 and $1300^{\circ} \mathrm{C}$ in air. J. Alloys Compd. 2008, 464, 434-439. [CrossRef]

19. Li, J.J.; Qian, Y.H.; Niu, D.; Zhang, M.M.; Liu, Z.M.; Li, M.S. Phase formation and microstructure evolution of arc ion deposited $\mathrm{Cr}_{2} \mathrm{AlC}$ coating after heat treatment. Appl. Surf. Sci. 2012, 263, 457-464. [CrossRef]

20. Schneider, J.M.; Sun, Z.; Mertens, R.; Uestel, F.; Ahuja, R. Ab initio calculations and experimental determination of the structure of $\mathrm{Cr}_{2} \mathrm{AlC}$. Solid State Commun. 2004, 130, 445-449. [CrossRef]

21. Bugnet, M.; Jaouen, M.; Mauchamp, V.; Cabioc'h, V.; Hug, G. Experimental and first-principles investigation of the electronic structure anisotropy of Cr2AlC. Phys. Rev. B 2014, 90, 195116. [CrossRef]

22. Bugnet, M.; Mauchamp, V.; Oliviero, E.; Jaouen, M.; Cabioc'h, T. Chemically sensitive amorphization process in the nanolaminated $\mathrm{Cr}_{2} \mathrm{AlC}(\mathrm{A}=\mathrm{Al}$ or $\mathrm{Ge})$ system from TEM in situ irradiation. J. Nucl. Mater. 2013, 441, 133-137. [CrossRef]

23. Walter, C.; Sigumonrong, D.P.; El-Raghy, T.; Schneider, J.M. Towards large area deposition of $\mathrm{Cr}_{2} \mathrm{AlC}_{\text {on steel. }}$ Thin Solid Films 2006, 515, 389-393. [CrossRef]

24. Li, J.J.; Hu, L.F.; Li, F.Z.; Li, M.S.; Zhou, Y.C. Variation of microstructure and composition of the $\mathrm{Cr}_{2} \mathrm{AlC}$ coating prepared by sputtering at 370 and $500{ }^{\circ}$ C. Surf. Coat. Technol. 2010, 204, 3838-3845. [CrossRef]

25. Zamulaeva, E.I.; Levashov, E.A.; Sviridova, T.A.; Shvyndina, N.V.; Petrzhik, M.I. Pulsed electrospark deposition of MAX phase $\mathrm{Cr}_{2} \mathrm{AlC}$ based coatings on titanium alloy. Surf. Coat. Technol. 2013, 235, 454-460. [CrossRef]

26. Mertens, R.; Sun, Z.; Music, D.; Schneider, J.M. Effect of the Composition on the Structure of Cr-Al-C Investigated by Combinatorial Thin Film Synthesis and ab Initio Calculations. Adv. Eng. Mater. 2004, 6, 903-907. [CrossRef] 
27. Field, M.R.; Carlsson, P.; Eklund, P.; Patridge, J.G.; McCulloch, D.G.; McKenzie, D.R.; Bilek, M.M.M. A combinatorial comparison of DC and high power impulse magnetron sputtered $\mathrm{Cr}_{2} \mathrm{AlC}$. Surf. Coat. Technol. 2014, 259, 746-750. [CrossRef]

28. Obrosov, A.; Naveed, M.; Volinsky, A.; Weiß, S. Substrate Frequency Effects on $\mathrm{Cr}_{x} \mathrm{~N}$ Coatings Deposited by DC Magnetron Sputtering. J. Mater. Eng. Perform. 2017, 26, 366-373. [CrossRef]

29. Grieseler, R.; Hähnlein, B.; Stubenrauch, M.; Kups, T.; Wilke, M.; Hopfeld, M.; Pezoldt, J.; Schaaf, P. Nanostructured plasma etched, magnetron sputtered nanolaminar $\mathrm{Cr}_{2} \mathrm{AlC}$ MAX phase thin films. Appl. Surf. Sci. 2014, 292, 997-1001. [CrossRef]

30. Wang, Q.M.; Flores, R.A.; Schroeter, O.; Mykhaylonka, R.; Leyens, C.; Garkas, W.; to Baben, M. Fabrication and oxidation behavior of $\mathrm{Cr}_{2} \mathrm{AlC}$ coating on Ti6242 alloy. Surf. Coat. Technol. 2010, 204, 2343-2352. [CrossRef]

31. Baben, M.; Shang, L.; Emmerlich, J.; Schneider, J.M. Oxygen incorporation in $\mathrm{M}_{2} \mathrm{AlC}(\mathrm{M}=\mathrm{Ti}, \mathrm{V}, \mathrm{Cr})$. Acta Mater. 2012, 60, 4810-4818. [CrossRef]

32. Naveed, M.; Obrosov, A.; Weiß, S. Investigation of the Wear Resistance Properties of Cr/CrN Multilayer Coatings against Sand Erosion. Conf. Pap. Sci. 2015, 2015, 873543. [CrossRef]

33. Gulyaev, R.V.; Koscheev, S.V.; Malykhin, S.E. An algorithm for removing charging effects from X-ray photoelectron spectra of nanoscaled non-conductive materials. J. Electron Spectrosc. Relat. Phenom. 2015, 202, 89-101. [CrossRef]

34. Oliver, W.C.; Pharr, G.M. An improved technique for determining hardness and elastic modulus using load and displacement sensing indentation experiments. J. Mater. Res. 1992, 7, 1564-1583. [CrossRef]

35. Thornton, J.A. High Rate Thick Film Growth. Annu. Rev. Mater. Sci. 1977, 7, 239-260. [CrossRef]

36. Berger, O.; Leyens, C.; Heinze, S.; Boucher, R.; Ruhnow, M. Characterization of Cr-Al-C and Cr-Al-C-Y films synthesized by High Power Impulse Magnetron Sputtering at a low deposition temperature. Thin Solid Films 2015, 580, 6-11. [CrossRef]

37. Dahlqvist, M.; Alling, B.; Abrikosov, I.A.; Rosén, J. Phase stability of $\mathrm{Ti}_{2} \mathrm{AlC}$ upon oxygen incorporation: A first-principles investigation. Phys. Rev. B 2010, 81, 024111. [CrossRef]

38. Shtansky, D.V.; Kiryukhantsev-Korneev, P.V.; Sheveyko, A.N.; Mavrin, B.N.; Rojas, C.; Fernandez, A.; Levashov, E.A. Comparative investigation of $\operatorname{TiAlC}(\mathrm{N}), \operatorname{TiCrAlC}(\mathrm{N})$, and $\operatorname{CrAlC}(\mathrm{N})$ coatings deposited by sputtering of MAX-phase $\mathrm{Ti}_{2}-{ }_{x} \mathrm{Cr}_{x}$ AlC targets. Surf. Coat. Technol. 2009, 203, 3595-3609. [CrossRef]

39. Hauert, R.; Patscheider, J.; Tobler, M.; Zehringer, R. XPS investigation of the a-C:H/Al interface. Surf. Sci. 1993, 292, 121-129. [CrossRef]

40. Lewin, E.; Gorgoi, M.; Schäfers, F.; Svensson, F. Influence of sputter damage on the XPS analysis of metastable nanocomposite coatings. Surf. Coat. Technol. 2009, 204, 455-462. [CrossRef]

41. Calderon, V.S.; Cavaleiro, A.; Carvalho, S. Chemical and structural characterization of ZrCNAg coatings: XPS, XRD and Raman spectroscopy. Appl. Surf. Sci. 2015, 346, 240-247. [CrossRef]

42. Vyas, A.; Shen, Y.G.; Zhou, Z.F.; Li, K.Y. Nano-structured $\mathrm{CrN} / \mathrm{CN}_{x}$ multilayer films deposited by magnetron sputtering. Compos. Sci. Technol. 2008, 68, 2922-2929. [CrossRef]

43. Ikemoto, I.; Kikujiro, I.; Shuichi, K.; Haruo, K.; Franco, A.; Thomas, J.M. X-ray photoelectron spectroscopic studies of $\mathrm{CrO}_{2}$ and some related chromium compounds. J. Solid State Chem. 1976, 17, 425-430. [CrossRef]

44. Healy, M.D.; Smith, D.C.; Rubiano, R.R.; Elliott, N.E.; Springer, R.W. Use of Tetraneopentylchromium as a Precursor for the Organometallic Chemical Vapor Deposition of Chromium Carbide: A Reinvestigation. Chem. Mater. 1994, 6, 448-453. [CrossRef]

45. Zamulaeva, E.I.; Levashov, E.A.; Skryleva, E.A.; Sviridova, T.A.; Kiryukhantsev-Korneev, P.V. Conditions for formation of MAX phase $\mathrm{Cr}_{2} \mathrm{AlC}$ in electrospark coatings deposited onto titanium alloy. Surf. Coat. Technol. 2016, 298, 15-23. [CrossRef]

46. Scofield, J.H. Theoretical Photoionization cross Sections from 1 to $1500 \mathrm{keV}$; Lawrence Livermore National Laboratory Report UCRL-51326; Lawrence Livermore National Laboratory: Livermore, CA, USA, 1973.

47. Agostinelli, E.; Battistoni, C.; Fiorani, D.; Nogues, M. An XPS study of the electronic structure of the $\mathrm{Zn}_{x} \mathrm{Cd}_{1-x} \mathrm{Cr}_{2}(\mathrm{X}=\mathrm{S}$, Se) spinel system. J. Phys. Chem. Solids 1989, 50, 269-272. [CrossRef]

48. Allen, G.C.; Tucker, P.M.; Wild, R.K. X-ray photoelectron/Auger electron spectroscopic study of the initial oxidation of chromium metal. J. Chem. Soc. Faraday Trans. 2 1978, 74, 1126-1140. [CrossRef]

49. Dejun, K.; Haoyuan, G. Friction-wear behaviors of cathodic arc ion plating AlTiN coatings at high temperatures. Tribol. Int. 2015, 88, 31-39. [CrossRef] 
50. Slavinskaya, E.M.; Stonkus, O.; Gulyaev, R.V.; Boronin, A.I. Structural and chemical states of palladium in $\mathrm{Pd} / \mathrm{Al}_{2} \mathrm{O}_{3}$ catalysts under self-sustained oscillations in reaction of $\mathrm{CO}$ oxidation. Appl. Catal. A Gen. 2011, 401, 83-97. [CrossRef]

51. Zhang, Z.; Nie, Y.; Shen, L.; Chai, J.; Pan, J.; Wong, L.M.; Sullivan, M.B.; Jin, H.; Wang, S.J. Charge Distribution in the Single Crystalline $\mathrm{Ti}_{2} \mathrm{AlN}$ Thin Films Grown on $\mathrm{MgO}(111)$ Substrates. J. Phys. Chem. C 2013, 117, 11656-11662. [CrossRef]

52. Zhang, Z.; Jin, H.; Chai, J.; Pan, J.; Seng, H.L.; Goh, G.T.W.; Wong, L.M.; Sullivan, M.B.; Wang, S.J. Temperature-dependent microstructural evolution of $\mathrm{Ti}_{2} \mathrm{AlN}$ thin films deposited by reactive magnetron sputtering. Appl. Surf. Sci. 2016, 368, 88-96. [CrossRef]

53. Gangopadhyay, S.; Acharya, R.; Chattopadhyay, A.K.; Paul, S. Effect of substrate bias voltage on structural and mechanical properties of pulsed DC magnetron sputtered TiN-MoS $x$ composite coatings. Vacuum 2010, 84, 843-850. [CrossRef]

54. Jiang, N.; Zhang, H.J.; Bao, S.N.; Shen, Y.G.; Zhou, Z.F. XPS study for reactively sputtered titanium nitride thin films deposited under different substrate bias. Phys. B Condens. Matter 2004, 352, 118-126. [CrossRef]

55. Kong, Q.; Ji, L.; Li, H.; Liu, X.; Wang, Y.; Chen, J.; Zhou, H. Influence of substrate bias voltage on the microstructure and residual stress of $\mathrm{CrN}$ films deposited by medium frequency magnetron sputtering. Mater. Sci. Eng. B 2011, 176, 850-854. [CrossRef]

56. Benegra, M.; Lamas, D.G.; de Rapp, M.E.F.; Mingolo, N.; Kunrath, A.O.; Souza, R.M. Residual stresses in titanium nitride thin films deposited by direct current and pulsed direct current unbalanced magnetron sputtering. Thin Solid Films 2006, 494, 146-150. [CrossRef]

57. Forniés, E.; Escobar, G.R.; Sánchez, O.; Albella, J.M. Growth of $\mathrm{CrN}_{x}$ films by DC reactive magnetron sputtering at constant N2/Ar gas flow. Surf. Coat. Technol. 2006, 200, 6047-6053. [CrossRef]

58. Heo, S.J.; Kim, S.W.; Yeo, I.W.; Park, S.J.; Oh, Y.S. Effect of bias voltage on microstructure and phase evolution of Cr-Mo-N coatings by an arc bonded sputter system. Ceram. Int. 2016, 42, 5231-5237.

59. Devia, D.M.; Restrepo-Parra, E.; Arango, P.J.; Tschiptschin, A.P.; Velez, J.M. TiAlN coatings deposited by triode magnetron sputtering varying the bias voltage. Appl. Surf. Sci. 2011, 257, 6181-6185. [CrossRef]

60. Olaya, J.J.; Rodil, S.E.; Muhl, S.; Sánchez, E. Comparative study of chromium nitride coatings deposited by unbalanced and balanced magnetron sputtering. Thin Solid Films 2005, 474, 119-126. [CrossRef]

61. Hultman, L.; Münz, W.-D.; Musil, J.; Kadlec, S.; Petrov, I.; Greene, J.E. Low-energy ( 100 eV) ion irradiation during growth of TiN deposited by reactive magnetron sputtering: Effects of ion flux on film microstructure. J. Vac. Sci. Technol. A 1991, 9, 434-438. [CrossRef]

62. Caicedo, J.C.; Yate, L.; Cabrera, G.; Pietro, P. Effect of negative bias voltage on mechanical and electrochemical nature in Ti-W-N coatings. J. Mater. Sci. 2010, 46, 1244-1252. [CrossRef]

63. Lee, C.-T.; Cho, W.-H.; Shiao, M.-H.; Hsiao, C.-N.; Tang, K.-S.; Jaing, C.-C. Effects of DC Bias on the Microstructure, Residual Stress and Hardness Properties of TiVCrZrTaN Films by Reactive RF Magnetron Sputtering. Procedia Eng. 2012, 36, 316-321. [CrossRef]

64. Banerjee, R.; Chandra, R.; Ayyub, P. Influence of the sputtering gas on the preferred orientation of nanocrystalline titanium nitride thin films. Thin Solid Films 2002, 405, 64-72. [CrossRef]

65. Zhang, T.F.; Gan, B.; Park, S.; Wang, Q.M.; Kim, K.H. Influence of negative bias voltage and deposition temperature on microstructure and properties of superhard TiB2 coatings deposited by high power impulse magnetron sputtering. Surf. Coat. Technol. 2014, 253, 115-122. [CrossRef]

66. Leyland, A.; Matthews, A. On the significance of the $H / E$ ratio in wear control: A nanocomposite coating approach to optimised tribological behaviour. Wear 2000, 246, 1-11. [CrossRef]

67. Anderson, P.M.; Li, C. Hall-Petch relations for multilayered materials. Nanostruct. Mater. 1995, 5, 349-362. [CrossRef]

68. Mounier, E.; Pauleau, Y. Mechanisms of intrinsic stress generation in amorphous carbon thin films prepared by magnetron sputtering. Diam. Relat. Mater. 1997, 6, 1182-1191. [CrossRef]

69. Carrasco, C.A.; Vergara, S.; Benavente, G.; Mingolo, N.; Ros, J.C. The relationship between residual stress and process parameters in TiN coatings on copper alloy substrates. Mater. Charact. 2002, 48, 81-88. [CrossRef]

70. Tang, C.; Klimenkov, M.; Jaentsch, U.; Leiste, H.; Ulrich, S.; Steinbrück, M.; Seifert, H.J.; Stueber, M. Synthesis and characterization of $\mathrm{Ti}_{2} \mathrm{AlC}$ coatings by magnetron sputtering from three elemental targets and ex-situ annealing. Surf. Coat. Technol. 2017, 309, 445-455. [CrossRef] 
71. Wilhelmsson, O.; Palmquist, J.-P.; Nyberg, T.; Jansson, U. Deposition of $\mathrm{Ti}_{2} \mathrm{AlC}$ and $\mathrm{Ti}_{3} \mathrm{AlC}_{2}$ epitaxial films by magnetron sputtering. Appl. Phys. Lett. 2004, 85, 1066-1068. [CrossRef]

72. Wang, Z.; Li, X.; Zhou, J.; Liu, P.; Huang, Q.; Ke, P.; Wang, A. Microstructure evolution of V-Al-C coatings synthesized from a $\mathrm{V}_{2} \mathrm{AlC}$ compound target after vacuum annealing treatment. J. Alloys Compd. 2016, 661, 476-482. [CrossRef]

73. Siumonrong, D.P.; Zhang, J.; Zhou, Y.; Music, D.; Schneider, J.M. Synthesis and elastic properties of $\mathrm{V}_{2} \mathrm{AlC}$ thin films by magnetron sputtering from elemental targets. J. Phys. D Appl. Phys. 2009, 42, 185408. [CrossRef]

74. Hall, E.O. The Deformation and Ageing of Mild Steel: III Discussion of Results. Proc. Phys. Soc. Sect. B 1951, 64, 747. [CrossRef]

(C) 2017 by the authors; licensee MDPI, Basel, Switzerland. This article is an open access article distributed under the terms and conditions of the Creative Commons Attribution (CC BY) license (http:/ / creativecommons.org/licenses/by/4.0/). 